\title{
Influência do Hormônio do Crescimento na concentração de testosterona plasmática e nas características seminais de touros jovens e adultos da raça Nelore
}

[Influence of Growth Hormone on plasma testosterone concentration and seminal characteristics of young and adult Nellore bulls]

\author{
L.S. Amorim ${ }^{1}$, T.S. Kawamoto ${ }^{1}$, C.A.A. Torres ${ }^{1}$, J.D. Guimarães ${ }^{1}$, J.M. Silva Filho ${ }^{2}$, M.M.N.F. Oliveira ${ }^{3}$, \\ G.R. Carvalho ${ }^{1}$, J.F. Fonseca ${ }^{4}$ \\ ${ }^{1}$ Universidade Federal de Viçosa - UFV - Viçosa, MG \\ ${ }^{2}$ Escola de Medicina Veterinária - UFMG - Belo Horizonte, MG \\ ${ }^{3}$ Universidade Federal dos Vales do Jequitinhonha e Mucuri - UFVJM - Diamantina, MG \\ ${ }^{4}$ Embrapa Caprinos - Sobral, CE
}

\begin{abstract}
RESUMO
Estudou-se o efeito do Hormônio do Crescimento bovino (bGH) sobre os parâmetros seminais e a concentração sérica de testosterona de touros da raça Nelore. Dezesseis touros foram distribuídos em um delineamento fatorial 2 × 2 (duas idades e dois níveis de r-bST), com quatro animais em cada tratamento. As aplicações de rbST foram realizadas a cada 14 dias, totalizando nove aplicações por animal, em um período experimental de 120 dias. As coletas de sêmen foram realizadas a cada 15 dias e, para determinar as concentrações de testosterona, foram realizadas coletas de sangue a cada quatro horas, num total de 24 horas, e a cada 30 dias a partir da primeira aplicação de r-bST. O sêmen dos touros adultos tratados com r-bST apresentaram maior motilidade e vigor $(\mathrm{P}<0,05)$ em relação aos animais controles $(79,70 \pm 11,56 \%$ vs $64,06 \pm 23,65 \%)$ e $(3,80 \pm 0,88$ vs 2,92 $\pm 1,25)$, respectivamente; entretanto, as demais características seminais não foram influenciadas $(\mathrm{P}>0,05)$ pelo tratamento com $\mathrm{r}-\mathrm{bST}$. Os aspectos físicos do sêmen dos touros jovens não foram afetados ( $\mathrm{P}>0,05)$ pelo tratamento com r-bST. Entretanto o tratamento com r-bST diminuiu os defeitos morfológicos menores (delgado, gigante normal, pequeno normal, globoso, cabeça isolada normal, abaxial, cauda dobrada e enrolada levemente e gota distal) em relação aos jovens não tratados $(\mathrm{P}<0,05)$. As concentrações séricas de testosterona foram influenciadas $(\mathrm{P}<0,05)$ pelo tratamento, aos 120 dias após a primeira aplicação do $\mathrm{r}-\mathrm{bST}$, e apresentaram tendência de três picos no período de 24 horas.
\end{abstract}

Palavras-chave: touro, hormônio, sêmen, Somatotrofina bovina recombinante (r-bST), testosterona

\begin{abstract}
The aim of this trial was to study the effect of Growth Hormone (GH) on the seminal parameters and testosterone profile from Nellore bulls. Sixteen bulls were allocated in a $2 \times 2$ factorial arrangement (two ages and two $r$-bST levels), with four animals per treatment. The r-bST was injected every 14 days, with a total of nine injections per animal, during the 120 days of the experimental period. The semen collections were done every 15 days and blood samples were collected in four hour intervals for 24 hours, and in 30 day intervals from the first $r$-bST injection for testosterone profile. The semen of adult bulls treated with $r$-bST showed greater MOT and VIG $(P<0.05)$ in relation to the control $(79.70 \pm 11.56 \%$ vs $64.06 \pm 23.65 \%)$ and $(3.80 \pm 0.88$ vs $2.92 \pm 1.25)$ respectively; however, the other evaluated seminal parameters were not affected $(P>0.05)$ by the $r$ $b S T$ treatment. The physical measurements of the semen of young animals was also unaffected $(P>0.05)$ by $r$ $b S T$ injection. However, the treatment with $r$-bST decreased the number of minor morphologic defects (narrow head, giant head, small normal head, round head, free normal head, abaxial implantation, simple bent tail and distal droplet) compared to untreated young bulls $(P<0.05)$. The serum testosterone concentration was influenced $(P<0.05)$ by treatment, at 120 days after the first injection of $r-b S T$ and they showed a tendency of three picks in a 24 hour period of sampling.
\end{abstract}

Keywords: bull, hormone, semen, recombinant bovine Somatotropin ( $r$-bST), testosterone

Recebido em 3 de setembro de 2013

Aceito em 13 de agosto de 2014

E-mail: lnlsamorimufv@gmail.com 


\section{INTRODUÇÃO}

Os distúrbios hormonais são as maiores causas de problemas relacionados à infertilidade masculina (Roser, 1995). Existe substancial evidência de que o hormônio do crescimento (GH, somatotropina) regula o crescimento somático e a diferenciação, afetando a função testicular, por modular a síntese de esteroides gonadais e a gametogênese (Zachman, 1992). A somatotrofina bovina (bST), ou hormônio do crescimento bovino (bGH), é produzido pelas células somatotróficas da hipófise anterior e tem sua ação controlada por uma somatomedina-C denominada IGF-I e outros metabólicos sanguíneos, como a glicose, ureia, ácidos graxos não esterificados, dentre outros (Amorim et al., 2007).

Os efeitos da deficiência de GH em ratos parece estarem associados com o comprometimento da espermatogênese e diminuição da motilidade espermática (Gravance et al., 1997), mas essas informações, bem como aquelas da influência exógena do tratamento com $\mathrm{GH}$ na espermatogênese em animais adultos, não estão disponíveis para a espécie bovina. Por outro lado, cães tratados com altas doses de GH humano mostraram degeneração testicular e redução do peso testicular (Sjögren et al., 1998).

Segundo Laron (1984), a aplicação de GH restabelece a puberdade em homens com deficiência de $\mathrm{GH}$ e mantém a espermatogênese normal. Além disso, Bartke et al. (1999) verificaram que a deficiência na decodificação de $\mathrm{GH}$ implica reduzida capacidade reprodutiva em fêmeas, declínio da performance reprodutiva de machos e alterações no eixo hipotalâmicohipofisário-gonadal (HPG). No entanto, Santos et al. (1999) demonstraram haver pouca influência do GH no rendimento da espermatogênese de touros adultos, e Gomes (2001) registrou diferença apenas na altura do epitélio seminífero de touros jovens.

Santos et al. (1999) não encontraram diferença entre as concentrações de LH e FSH em touros adultos da raça Nelore tratados com r-bST (Somatotrofina bovina recombinante) (500mg) quando comparados aos controles, porém observaram maiores concentrações de IGF-I nos animais tratados. Mani Maran et al. (2000) mostraram em experimentos in vitro que o $\mathrm{GH}$ estimulou a secreção de testosterona pelas células de Leydig e também modulou a ação do LH na secreção desse esteroide.

Sabe-se que o hormônio do crescimento (GH) possui receptores nas células testiculares, podendo agir diretamente nestas, sendo dependente da idade (N'Diaye et al., 2002). Entretanto, o r-bST em bovinos parece não afetar as concentrações de testosterona durante a prépuberdade/puberdade (MacDonald e Deaver, 1993).

Com a obtenção da somatotropina bovina pela técnica do DNA recombinante (rbST), adquiriuse um número cada vez maior de informações a respeito da ação do GH exógeno em ruminantes. Entretanto, seus efeitos em machos ainda permanecem não totalmente esclarecidos, especialmente em características com grande impacto no desempenho animal.

Nas situações em que linhagens de excepcional mérito genético apresentam diminuição da fertilidade, sem que se caracterize um processo hereditário, devem-se considerar procedimentos terapêuticos na tentativa de restabelecer o desempenho reprodutivo. Nessas circunstâncias, o uso de substâncias naturais ou sintéticas, como o GH ou a r-bST, pode ser uma alternativa viável.

Objetivou-se, portanto, estudar as características físicas e morfológicas do sêmen e as concentrações séricas de testosterona de animais jovens e adultos da raça Nelore, submetidos ou não ao tratamento por r-bST.

\section{MATERIAL E MÉTODOS}

Foram utilizados 16 touros da raça Nelore, previamente avaliados quanto ao seu potencial reprodutivo por meio de exame andrológico, de acordo com os critérios do Colégio Brasileiro de Reprodução Animal (Colégio..., 1998) e divididos segundo as características seminais em: jovens $(\mathrm{J})$ - que se encontravam em fase puberal -; adultos (A) - que se apresentavam maturos sexualmente, os quais foram utilizados como doadores de sêmen. Os critérios utilizados na classificação sexual dos touros foram baseados na qualidade seminal. Para touros adultos, os ejaculados apresentaram $50 \%$ de motilidade progressiva, defeitos maiores não superiores a $30 \%$ e defeitos menores de no máximo $15 \%$, conforme as normas do Colégio Brasileiro de 
Reprodução Animal (Colégio..., 1998). Para os animais jovens, estes foram classificados quando suas características seminais eram inferiores às estabelecidas para touros adultos (Lunstra, 1978). Antes do início do experimento, os animais foram submetidos à adaptação de 15 dias à dieta e ao manejo de coletas de sêmen. Estes foram distribuídos em quatro tratamentos conforme a idade (touros jovens e adultos) e dose de hormônio do crescimento (0 e 500mg de rbST), constituindo um delineamento fatorial $2 \mathrm{x}$ 2. Cada tratamento continha quatro repetições, distribuídos aleatoriamente, sendo denominados: touros jovens controle (JC), touros jovens tratados (JT), touros adultos controle (AC) e touros adultos tratados (AT). Os animais tratados receberam, a cada 14 dias, a aplicação via subcutânea de 500mg de sometribove zinco $\left(\right.$ LACTOTROPIN $^{\circledR}$ Injetável - Somatotrofina Bovina Recombinante - r-bST, Elanco saúde animal - Brasil Ltda.), de liberação lenta, durante os 120 dias do período experimental, perfazendo um total de nove aplicações por animal. Os animais controle receberam solução salina (placebo). Ao início do período experimental, os animais jovens e adultos apresentavam idades

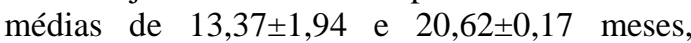
respectivamente, e peso corporal de $407,00 \pm 11,31 ; 352,50 \pm 3,53 \mathrm{~kg}$, respectivamente.

Os animais foram mantidos em baias individuais de $8 \mathrm{~m}^{2}$, distribuídas em um galpão de alvenaria com cobertura de telha de barro, e alimentação e manejo foram os mesmos descritos por Amorim et al. (2007).

Amostras de sêmen foram coletadas pelo método de eletroejaculação com intervalos de 15 dias, e submetidas à avaliação das características físicas [volume seminal (Vol), turbilhonamento (Turb), motilidade espermática progressiva retilínea (Mot) e vigor espermático] e morfológicas [defeitos maiores (DM), menores (Dm) e totais (DT)], segundo (Blom, 1973).

Para a concentração espermática, seguiu-se a recomendação de Hancock (1957).

A concentração sérica de testosterona foi determinada a cada 30 dias, a partir da primeira aplicação de r-bST. Amostras de sangue foram obtidas por punção da veia jugular em tubos vacutainer $^{\circledR}$ e mantidas em caixa de isopor com banho de gelo, até sua centrifugação, o que não excedeu 45 minutos pós-coleta. As amostras foram centrifugadas a $1.000 \mathrm{X} \mathrm{g}$ por 15 minutos, o soro foi aspirado e acondicionado em tubos plásticos de $1,5 \mathrm{~mL}$ que foram armazenados a $20^{\circ} \mathrm{C}$ até as análises.

Em cada sessão de coleta, as amostras de sangue foram obtidas a intervalos de quatro horas, durante 24 horas (Santos et al., 2000), com início às $08: 30 \mathrm{~h}$ e término às 04:30h, visando-se registrar os picos e a média das variações diárias das concentrações séricas de testosterona (Barbosa, 1987). A concentração de testosterona foi determinada por radioimunoensaio ( ${ }^{125}$ I RIA) em duplicata em um único ensaio, pela utilização de kits comerciais de fase sólida (Testosterona Total - Coat-a-count - DPC - Diagnostic Products Corporation - Los Angeles - USA). A sensibilidade do teste foi de $0,04 \mathrm{mg} / \mathrm{dL}$, com coeficientes de variação intraensaio e interensaio de $11 \%$ para $0,087 \mathrm{ng} / \mathrm{mL}$ e de $7,3 \%$ para $13,00 \pm 0,95 \mathrm{ng} / \mathrm{mL}$, respectivamente.

Para análise estatística, utilizou-se o programa SAEG 8.0 (Sistema..., 2000), aplicando-se análise de variância para as variáveis: defeitos maiores e defeitos menores, tendo como fonte de variação os períodos de coleta e as idades. As diferenças observadas na análise de variância foram estudadas pelo teste Tukey com 5\% de probabilidade de erro. Os dados de vigor e motilidade espermáticos foram avaliados pela análise de variância não paramétrica e submetidos ao teste de Kruskal-Wallis, a 5\% de probabilidade de erro. $\mathrm{O}$ volume do ejaculado foi apresentado como média e desvio padrão.

\section{RESULTADOS E DISCUSSÃO}

A análise de variância para alguns dos parâmetros físicos do sêmen avaliados mostrou que houve diferença significativa para as duas idades e para o tratamento ou não com r-bST $(\mathrm{P}<0,05)$ (Tab. 1).

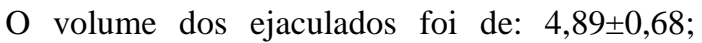
$4,01 \pm 0,99 ; \quad 5,96 \pm 1,62$ e $5,70 \pm 0,34 \mathrm{~mL}$, respectivamente, para JC, JT, AC e AT (Tab. 1), e esses dados não foram submetidos à ANOVA por causa da variação destes em função da intensidade dos estímulos elétricos do método de coleta empregado. Entretanto, Sauerwein et al. (2000) observaram que o tratamento com r-bST promoveu diminuição do volume do ejaculado em touros. 
Tabela 1. Valores médios e desvios padrão dos aspectos físicos do sêmen de touros da raça Nelore (Bos taurus indicus), tratados ou não com r-bST

\begin{tabular}{lcccc} 
& \multicolumn{4}{c}{ Tratamentos } \\
\cline { 2 - 5 } Parâmetros & JC & JT & AC & AT \\
\hline Volume $(\mathrm{mL})$ & $4,89 \pm 0,68$ & $4,01 \pm 0,99$ & $5,96 \pm 1,62$ & $5,70 \pm 0,34$ \\
Turb $(0-5)$ & $1,63 \pm 1,27 \mathrm{~b}$ & $1,60 \pm 1,69 \mathrm{~b}$ & $2,12 \pm 1,46 \mathrm{ab}$ & $3,12 \pm 1,25 \mathrm{a}$ \\
Mot $^{* *}(\%)$ & $45,94 \pm 35,61 \mathrm{a}$ & $48,75 \pm 33,47 \mathrm{a}$ & $64,06 \pm 23,65 \mathrm{a}$ & $79,70 \pm 11,56 \mathrm{~b}$ \\
Vigor $^{* *}(0-5)$ & $2,81 \pm 3,40 \mathrm{a}$ & $2,16 \pm 1.67 \mathrm{a}$ & $2,92 \pm 1,25 \mathrm{a}$ & $3,80 \pm 0,88 \mathrm{~b}$ \\
Conc. $\left(\times 10^{6} / \mathrm{mL}\right)$ & $54,50 \pm 4,38 \mathrm{~b}$ & $45,59 \pm 2,95 \mathrm{~b}$ & $342,47 \pm 11,22 \mathrm{a}$ & $364 \pm 15,37 \mathrm{a}$ \\
\hline
\end{tabular}

JT: Jovens tratados com r-bST; JC: Jovens não tratados; AT: Adultos tratados com r-bST; AC: Adultos não tratados. TURB - turbilhonamento; MOT - motilidade espermática progressiva retilínea; VIG - vigor espermático. ${ }^{* *}$ Análise não paramétrica. Médias seguidas de pelo menos uma mesma letra minúscula na linha não diferem entre si pelo teste Tukey $(\mathrm{P}>0,05)$.

Nos touros adultos, as características físicas do sêmen, tais como motilidade e vigor, foram influenciadas pelo tratamento com r-bST $(\mathrm{P}<0,05$; Tab. 1). A maior motilidade e vigor apresentados pelos animais tratados estão de acordo com os resultados obtidos por Sauerwein et al. (2000), que verificaram valores superiores em touros tratados com r-bST. Entretanto, Garcia (2004) não verificou diferença entre as características físicas do sêmen de touros tratados ou não com r-bST.

Para os grupos de animais jovens não foram observadas diferenças para nenhuma das características físicas do sêmen analisadas $(\mathrm{P}>0,05)$ entre os animais tratados ou não com $\mathrm{r}$ bST. Porém, houve diferença dessas características entre os animais jovens tratados ou não com os touros adultos tratados $(\mathrm{P}<0,05$; Tab. 1), demonstrando efeito da interação dos resultados no presente experimento.

Os efeitos do r-bST, GH ou p-ST sobre aspectos seminais podem ser obervados em diferentes modelos de estudos, com resultados positivos e negativos. Sabe-se que o hormônio do crescimento possui receptores testiculares que poderiam ser capazes de provocar maior eficiência na espermatogênese e esteroidogênese, culminando com a melhora da motilidade e de outros parâmetros seminais. Tal efeito pode variar em relação à idade dos animais (N'Diaye et al., 2002). Há, também, uma ação indireta do r-bST, GH ou p-ST que seria através do aumento dos níveis circulantes de IGF-I; esse aumento promoveria um incremento no metabolismo espermático. Dessa maneira, seria observado um aumento nas concentrações de lactato e glicose seminais (Stewart e Rotwein, 1996).

A concentração espermática não diferiu entre os animais jovens e adultos, independentemente do tratamento com r-bST (Tab. 1). Entretanto, Sauerwein et al. (2000) verificaram aumento da concentração espermática em animais tratados com r-bST.

Houve efeito do tratamento com r-bST em relação aos aspectos morfológicos do sêmen (Tab. 2).

Tabela 2. Médias dos aspectos morfológicos do sêmen de touros da raça Nelore (Bos taurus indicus), tratados ou não com r-bST

\begin{tabular}{lcccc} 
& \multicolumn{4}{c}{ Tratamentos } \\
\cline { 2 - 5 } Parâmetros & JC & JT & AC & AT \\
\hline DM(\%) & $36,87 \pm 23,87 \mathrm{a}$ & $33,78 \pm 28,6 \mathrm{ab}$ & $19,60 \pm 15,78 \mathrm{bc}$ & $8,73 \pm 5,68 \mathrm{c}$ \\
Dm(\%) & $11,17 \pm 1,84 \mathrm{a}$ & $5,82 \pm 2,96 \mathrm{~b}$ & $7,98 \pm 7,00 \mathrm{ab}$ & $5,98 \pm 4,44 \mathrm{~b}$ \\
$\mathrm{DT}(\%)$ & $46,83 \pm 22,41 \mathrm{a}$ & $39,60 \pm 29,9 \mathrm{ab}$ & $27,58 \pm 19,89 \mathrm{bc}$ & $14,72 \pm 7,95 \mathrm{c}$ \\
\hline
\end{tabular}

JT: Jovens tratados com r-bST; JC: Jovens não tratados; AT: Adultos tratados com r-bST; AC: Adultos não tratados. DM - Defeitos Maiores; Dm - Defeitos menores; DT - Defeitos totais. Médias seguidas de pelo menos uma mesma letra minúscula na linha diferem entre si pelo teste de Tukey $(\mathrm{P}>0,05)$.

Os defeitos espermáticos foram influenciados $(\mathrm{P}<0,05)$ pela aplicação de $\mathrm{r}-\mathrm{bST}$ para os touros jovens, e não diferiram $(\mathrm{P}>0,05)$ para os animais adultos. Sauerwein et al. (2000) e Hafez et al. (2005) também observaram diminuição das patologias espermáticas em touros tratados com 
r-bST, contrastando com os resultados de Vieira et al. (2010). Para os touros JC, os percentuais médios de defeitos espermáticos maiores e totais foram semelhantes ao JT $(\mathrm{P}>0,05)$, porém, diferiram dos animais AC e AT $(\mathrm{P}<0,05)$.

Já para os touros JT, todos os parâmetros de morfologia espermática mostraram-se semelhantes aos dos touros $\mathrm{AC}(\mathrm{P}>0,05)$, porém diferiram dos dos touros AT $(\mathrm{P}<0,05)$. Assim, observa-se que o tratamento com r-bST, para touros jovens, melhorou a qualidade seminal destes por equiparar-se aos resultados obtidos para touros adultos. Os defeitos espermáticos menores foram inferiores para os touros JT em relação aos touros $\mathrm{JC}(\mathrm{P}<0,05)$, embora ambos não diferiram dos animais $\mathrm{AC}(\mathrm{P}>0,05)$, e os touros JC apresentaram valores superiores aos dos animais AT $(\mathrm{P}<0,05)$. Os elevados valores das anomalias espermáticas, verificados nos animais jovens, provavelmente se devam à imaturidade dos mesmos, visto que a espermatogênese tenha melhor eficiência em animais adultos e seja incompleta nos animais jovens, devido à incompleta maturação dos ductos epididimários e das glândulas sexuais acessórias. Tais observações foram também relatadas por Guimarães (1993) e SchimidtHebbel et al. (2000) em touros jovens de raças indianas e indianas/taurinas, respectivamente.

Pela primeira vez, foi observado efeito positivo do r-bST em parâmetros morfológicos do sêmen de touros jovens, apresentando uma diminuição dos defeitos espermáticos. E ainda observou-se uma equivalência dos parâmetros seminais desses com os de animais adultos. Portanto, o uso terapêutico do r-bST frente a uma condição desfavorável na espermatogênese, como no caso da puberdade, pode ser eficaz para melhorar o quadro de patologias espermáticas. Estudos que utilizaram o r-bST em ratos e humanos com deficiência na espermatogênese também evidenciaram tal efeito (Laron, 1984; Bartke et al. 1999). Outro efeito benéfico do r-bST ocorreu em touros adultos, nos quais a espermatogênese já está estabelecida; mesmo assim, esta promoveu uma melhora no número de células morfologicamente normais. Parece existir um efeito do r-bST sobre os testículos e epidídimos dos animais tratados, já que houve alteração no número de defeitos morfológicos dos touros JT.

Quanto às concentrações séricas de testosterona determinadas em amostras coletadas aos 30 dias do período experimental, não se observou efeito da r-bST $(\mathrm{P}>0,05)$ em relação aos diferentes horários de coleta e dos tratamentos experimentais (JT, JC, AT e AC). Entretanto, nas amostras coletadas aos 60 dias do período experimental, houve somente efeito $(\mathrm{P}<0,05)$ da coleta realizada ao longo do dia. Assim, foram observados dois picos de aumento nas concentrações séricas de testosterona, às 16:30 h e às 08:30 h da manhã, com valores médios de $11,69 \mathrm{ng} / \mathrm{mL}$ e 5,41ng/mL, respectivamente. Aos 90 dias do período experimental, observou-se uma tendência $(\mathrm{P}=0,056)$ de efeito da coleta durante o período de 24 horas. Entretanto, para o mesmo período não houve efeito do tratamento $(\mathrm{P}>0,05)$ sobre as concentrações séricas de testosterona. Aos 120 dias do período experimental, as concentrações séricas de testosterona foram influenciadas $(\mathrm{P}<0,05)$ pelo tratamento com r-bST, sendo que os animais do grupo AT apresentaram maior concentração que os de AC, JT e JC (dados não mostrados). Na Tabela 3, são apresentadas as médias e os desvios padrão, quando as concentrações de testosterona foram agrupadas por horário de coleta durante as 24 horas, independentemente dos períodos de coleta (30, 60, 90 e 120 dias), representando, assim, todo o período experimental.

Tabela 3. Média geral e desvios padrão da concentração sérica de testosterona $(\mathrm{ng} / \mathrm{mL})$ para touros da raça Nelore (Bos taurus indicus), tratados ou não com r-bST, durante todo o período experimental

\begin{tabular}{lcccccc}
\hline Tratamentos & \multicolumn{7}{c}{ Horários de coletas } \\
\cline { 2 - 7 } & $08: 30$ & $12: 30$ & $16: 30$ & $20: 30$ & $00: 30$ & $04: 30$ \\
\hline JC & $4,48 \pm 1,94$ & $5,65 \pm 1,18$ & $6,37 \pm 5,64$ & $4,02 \pm 1,65$ & $5,11 \pm 1,15$ & $3,19 \pm 3,00$ \\
JT & $4,94 \pm 2,43$ & $4,09 \pm 1,89$ & $5,57 \pm 3,48$ & $2,99 \pm 1,53$ & $4,29 \pm 2,24$ & $3,30 \pm 1,82$ \\
AC & $7,15 \pm 2,68$ & $7,85 \pm 1,15$ & $7,15 \pm 5,04$ & $4,76 \pm 0,71$ & $5,93 \pm 2,22$ & $5,41 \pm 3,15$ \\
AT & $7,64 \pm 4,31$ & $3,87 \pm 2,09$ & $6,91 \pm 5,64$ & $5,40 \pm 3,57$ & $5,09 \pm 2,60$ & $6,49 \pm 3,20$ \\
\hline
\end{tabular}

JT: Jovens tratados com r-bST; JC: Jovens não tratados; AT: Adultos tratados com r-bST; AC: Adultos não tratados. 
As variações registradas para as concentrações séricas de testosterona (ng/mL) estão relacionadas ao padrão de secreção circadiano. Dessa forma, as variações nos resultados podem ser em função desses picos de secreção e da meia-vida dos hormônios esteroides, que é de cerca de trinta minutos a uma hora (Greenspan e Strewler, 1997).

Embora não caracterizados como picos, houve tendência de ocorrer elevação das concentrações de testosterona às 08:30, 16:30 e 00:30h (Fig. 1), corroborando os resultados de Santos (1996), que registrou tendência de picos de testosterona em touros da raça Nelore nos mesmos horários. Sanwal et al. (1974) observaram picos de secreção de testosterona próximo às 06:00, 12:00 e 22:00h, valores similares aos registrados por Barbosa (1987) em touros da raça Nelore, às 06:00, 14:00 e 22:00h.

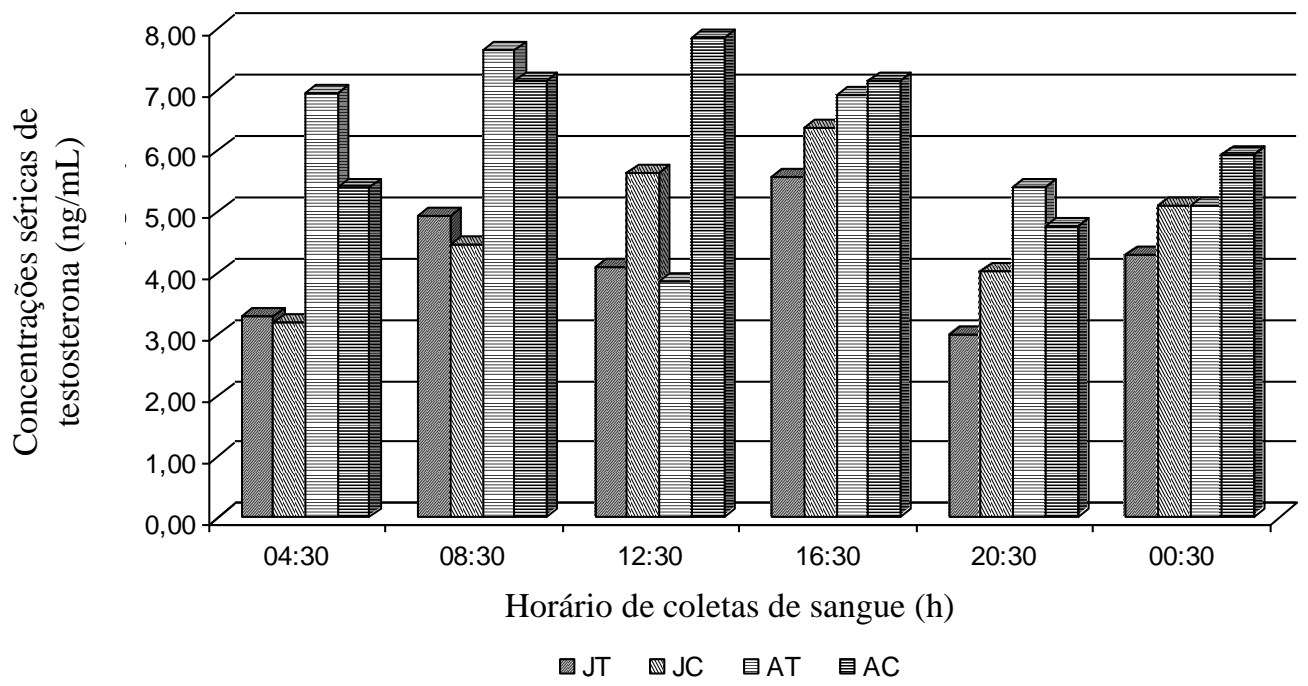

Figura 1. Concentrações médias de testosterona $(\mathrm{ng} / \mathrm{mL})$ de touros da raça Nelore (Bos taurus indicus), tratados ou não com r-bST, para as quatro sessões de coletas, realizadas ao longo do período experimental.

JT: Jovens tratados com r-bST; JC: Jovens não tratados; AT: Adultos tratados com r-bST; AC: Adultos não tratados.

Doses menores de r-bST aplicadas diariamente não foram efetivas em alterar as concentrações de testosterona em bovinos jovens de até 10 meses de idade $(0,2 \mathrm{mg} / \mathrm{Kg})$ (MacDonald e Deavers, 1993). Da mesma maneira, Wise et al. (1996) também não encontraram diferença com a administração de somatotrofina suína em varrões. Contrariamente, os resultados de Sauerwein et al. (2000) indicaram efeito da aplicação de 640mg de r-bST, a cada 14 dias, sobre as concentrações plasmáticas de testosterona, sem efeito sobre as concentrações seminais, corroborando as concentrações séricas de testosterona do presente experimento. Além disso, o r-bST pode influenciar a concentração de outros hormônios andrógenos, responsáveis pela espermatogênese (Mani Maran et al., 2000). Tal efeito pode ser responsável pela alteração dos parâmetros seminais de animais tratados com rbST de modo positivo, ratificando o uso desse hormônio de forma terapêutica.

\section{CONCLUSÃO}

O tratamento com r-bST aumentou a motilidade e o vigor espermático de touros adultos tratados, porém não afetou os aspectos físicos do sêmen de touros jovens. O r-bST diminuiu os defeitos espermáticos menores do grupo de touros jovens, e equiparou-os aos animais adultos quanto aos defeitos maiores, menores e totais. $\mathrm{O}$ tratamento com r-bST aumentou as concentrações de testosterona plasmática em animais adultos. 


\section{AGRADECIMENTOS}

Ao CNPq e à CAPES pela bolsa de estudos e compra do kit hormonal. À Associação Mineira dos Criadores de Gado Zebu - AMCZ - pelo apoio logístico. À Fazenda Aguadinha, Curvelo, Minas Gerais, pela compra do hormônio do crescimento (r-bST) e pelo suporte na realização do experimento de campo, animais e instalações.

\section{REFERÊNCIAS}

AMORIM, L.S.; TORRES, C.A.A.; MORAES, E.A. et al. Perfil metabólico de touros da raça Nelore (Bos taurus indicus) confinados e tratados com somatotrofina bovina recombinante (r-bST). Arq. Bras. Med. Vet. Zootec., v.59, p.434-442, 2007.

BARBOSA, R.T. Comportamento sexual, biometria testicular, aspectos do sêmen e níveis plasmáticos de testosterona em touros Canchin e Nelore. 1987. 135f. Dissertação (Mestrado em Medicina Veterinária) - Escola de Veterinária, Universidade Federal de Minas Gerais, Belo Horizonte.

BARTKE, A.; CHANDRASHERKAR, V.; TURYN, D. et al. Effect of growth hormone overexpression and growth hormone resistance on neuroendocrine and reproductive functions in transgenic and Knock-Out mice ${ }^{2}$ (44434) Minireview. Proc. Soc. Exp. Biol. Med., v.222, p.113-123, 1999.

BLOM, E. The ultrastructure of some characteristic sperm defects and a proposal for a new classification of the bull spermiogram. Nord. Vet. Med., v.25, p.383-391, 1973.

COLÉGIO Brasileiro De Reprodução Animal CBRA. Manual para exame andrológico $e$ avaliação do sêmen animal. 2.ed. Belo Horizonte: 1998. p.49.

GARCIA, A.R. Efeitos do estresse térmico e do uso da somatotropina bovina recombinante bovina nas características seminais, integridade das membranas, função mitocondrial e estrutura da cromatina de espermatozóides de touros Simental (Bos taurus taurus). 2004. 258f. Tese (Doutorado em Medicina Veterinária) Universidade de São Paulo, Pirassununga.
GOMES, G.S. Influência da somatotrofina bovina recombinante (RBST) sobre o ganho de peso e desenvolvimento testicular de novilhos de corte. 2001. 51f. Dissertação (Mestrado em Zootecnia) - Universidade Federal de Lavras, Lavras.

GRAVANCE, C.G.; BREIER, B.H.; VICKERS, M.H.; CASEY, P.J. Impaired sperm characteristics in postpubertal growth-hormonedeficient dwarf (dw/dw) rats. Anim. Reprod. Sci., v.59, p.71-76, 1997.

GREENSPAN, F.S.; STREWLER, J.G. (5.Ed.) Basic and clinic endocrinology. Estados Unidos da América: APLETTON and LANGE, 1997. $823 \mathrm{p}$.

GUIMARÃES, J.D. Puberdade e maturidade sexual em touros da raça Gir criados em condições semi-extensivas. 1993. 85f. Dissertação (Mestrado em Medicina Veterinária) - Escola de Veterinária, Universidade Federal de Minas Gerais, Belo Horizonte.

HAFEZ, Y.M.; FAWZY, S.A.; EL-HENAWY, M.A.; BARKAWY, A.H. Effect of recombinant bovine somatotropin (rbST) on semen physical characteristics and some biochemical constituents in seminal plasma of Friesian bulls. Egypt. J. Anim. Prod., v.42, p.87-94, 2005.

HANCOCK, J.L. The morphological of boar spermatozoa. J. R. Microsc. Soc., v.76, p.84-97, 1957.

LARON, Z. Laron-type dwarfism, hereditary somatomedin deficiency. A review. Ergeb. Inn. Med. Kinderheilkd., v.51, p.117-140, 1984.

LUNSTRA, D.D.; FORD, J.J.; ECHTERNKAMP, S.E. Puberty in beef bulls: hormone concentrations, growth, testicular development, sperm production and sexual aggressiveness in bulls of different breeds. J. Anim. Sci., v.46, p.1054-1062, 1978.

MacDONALD, R.D.; DEAVERS, D.R. Testicular development in bulls treated with recombinant bovine somatotropin. J. Anim. Sci., v.71, p.1540-1545, 1993.

MANI MARAN, R.R.M.; SIVAKUMAR, R.; RAVISNAKAR, B. et al. Growth hormone directly stimulates testosterone and oestradiol secretion by rat Leydig cells in vitro and modulates the effect of LH and T3. Endocr. J., v.47, p.111-118, 2000. 
N'DIAYE, M.R.; SUN, S.S.; FANUA, S.P. et al. Growth hormone receptors in the porcine testis during prepuberty. Reprod. Domest. Anim., v.37, p.305-309, 2002.

ROSER, J.F. Endocrine regulation of reproduction function in fertile, subfertile and infertile stallions. Reprod. Domest. Anim., v.30, p.245-250, 1995.

SANTOS, M.D. Perfil de testosterona $e$ metabólitos lipídicos, circunferência escrotal e aspectos do sêmen de touros Zebu alimentados com dois níveis de concentrado e lipídeo. 1996. 68f. Dissertação (Mestrado em Zootecnia), Universidade Federal de Viçosa, Viçosa.

SANTOS, R.L.; SILVA, C.M.; RIBEIRO, A.F.C. et al. Effect of growth hormone and induce IGF-1 release on germ cell population and apoptosis in the bovine testis. Theriogenology, v.51, p.975-984, 1999.

SANTOS, M.D.; TORRES, C.A.A.; RUAS, J.R.M. et al. Concentração de testosterona em touros Zebu. Rev. Bras. Zootec., v.20, p.738-744, 2000 .

SANWAL, P.C.; SUNDBY, A.; EDQVIST, L.E. Diurnal variation of peripheral plasma levels of testosterone in bulls measured by rapid radioimmunoassay procedure. Acta Vet. Scand., v.15, p.90-99, 1974.

SAUERWEIN, H.; BREIER, B.H.; GALLAHER, B.W. et al. Growth hormone treatment of breeding bulls used for artificial insemination improves fertilization rates. Domest. Anim. Endocrin., v.18, p.145-158, 2000.
SCHIMIDT-HEBBEL, J.; TONIOLLO, G.H.; LEITE, F.G. et al. Características físicas e morfológicas de sêmen de touros jovens das raças Gir, Guzerá, Nelore (Bos taurus indicus) e Caracu (Bos taurus taurus). Arq. Bras. Med. Vet. Zoo., v.52, p.461-467, 2000.

SISTEMA para análises estatísticas e genéticas Central de processamento de dados - CPD UFV. SAEG -. Viçosa, 2000.

SJÖGREN, I.; JÖNSSON, M.; MADEJ, A. et al. Effects of very high doses of human growth hormone $(\mathrm{hGH})$ on the male reproductive system in the dog. Andrologia, v.30, p.37-42, 1998.

STEWART, C.E.; ROTWEIN, P. Growth, differentiation, and survival: multiple physiological functions for insulin-like growth factors. Physiol. Rev., v.76, p.1005-1026, 1996.

VIEIRA, M.; BIANCHI, I.; MADEIRA, E. et al. Effect of recombinant bovine somatotropin on plasma concentrations of insulin-like growth factor I, insulin and membrane integrity of bull spermatozoa. Reprod. Dom. Anim., v.45, p.11101113, 2010.

ZACHMAN, M. Interrelations between growth hormone and sex hormones - physiology and therapeutic consequences. Horm. Res., v.38, p.18, 1992.

WISE, T.; KLINDT, J.; FORD, J.J. et al. Effects of porcine somatotropin on circulation testosterone concentration in boars and mechanism of action. J. Anim. Sci., v.74, p.30013011, 1996. 